\title{
Gilles de la Tourette syndrome: clinical features of 75 cases from Argentina
}

\author{
F. Micheli ${ }^{1}$, M. Gatto ${ }^{1}$, O. Gershanik ${ }^{2}$, A. Steinschnaider ${ }^{3}$, M. Fernandez Pardal ${ }^{1}$ \\ and M. Massaro ${ }^{3}$ \\ ${ }^{1}$ Department of Neurology, Hospital de Clinicas, University of Buenos Aires, ${ }^{2}$ Department of \\ Neurology, Hospital Frances, Buenos Aires, and ${ }^{3}$ Department of Neurology, Juan P. Garrahan \\ Pediatrics Hospital, Buenos Aires, Argentina
}

Correspondence to: F. Micheli, Olleros 2240 - 1426, Buenos Aires, Argentina

\begin{abstract}
A series of 75 cases of Gilles de la Tourette syndrome (GTS) from Argentina, whose ages ranged from 6 to 55 with a mean of 20.02, were evaluated to compare findings with those reported for other countries. Mean age at onset was 7.44 years and mean overall duration of symptoms was 12.58 years; $6.7 \%$ of cases were mild, $49 \%$ moderate and $44.3 \%$ severe. Most frequent presenting motor tics were excessive blinking in $\mathbf{4 1}$ followed by head jerking in 16 and eye winking in six, while phonic tics included coprolalia in $\mathbf{2 8 . 0} \%$, echolalia in $\mathbf{1 7 . 5 \%}$ and palilalia in $10.8 \%$. Abnormal perinatal events were reported in $40.5 \%$, while positive family history for tics was present in $26.66 \%$. Obsessive-compulsive behaviour was evident in $66 \%$ and attention deficit disorder in $16 \%$ of cases. Self-injurious behaviour comprised onychophagia in 28 patients, lip-biting in seven and self-slapping in eight cases. Almost half of our patients were initially interpreted as having a psychogenic disorder indicating that GTS in Argentina is most likely underdiagnosed. It may be concluded that the overall pattern of GTS is not dissimilar to that described for European, Asian and American populations, thus highlighting the previously recognized crosscultural uniformity.
\end{abstract}

Keywords: Argentina - Gilles de la Tourette - Obsessive-compulsive disorder - Tic

\section{INTRODUCTION}

Gilles de la Tourette syndrome (GTS) has long been recognized as a hereditary disorder featuring motor and phonic tics with early onset that wax and wane and change in nature over time.

Although named after Georges Gilles de la Tourette in 1885 , a previous case had already been described by Itard as early as 1825 (Itard, 1825).

Considered a rare neuropsychiatric disorder for decades, it was only in the last 30 years that GTS attracted the increasing attention of research workers who laid down criteria for its diagnosis. The classic triad of multiple tics, coprolalia and echolalia lost its paramount significance as shown by currently accepted criteria, thus providing the basis for earlier diagnosis even in mild cases (DSM-III-R; American Psychiatric Association, 1987). It is now widely accepted that GTS is a neuropsychiatric condition, and it has recently been demonstrated by neurophysiological techniques that motor tics are expressed by pathways other than those subserving voluntary movements (Obeso et al., 1981).

So far the occurrence of GTS in Latin America has been mostly documented as single case reports or very limited series in regional literature from Brazil (Sougey and Vilaca, 1981; Matarazzo, 1985; Rolemberg et al., 1985; Fontanari and Vaitses, 1985, 1986; Golfeto et al., 1988), Peru (Warton, 1987), Chile (Guajardo, 1986) and Puerto Rico (Joy Sobrino et al., 1985). In fact, only two papers are available in the English language journals describing a few cases from Argentina (Micheli et al., 1990) and a single case from Guyana (Eapen and Robertson, 1992).

Here we report the clinical features of 75 patients with GTS in Argentina evaluated over a 4 year period in the city of Buenos Aires.

\section{METHODS}

We evaluated prospectively 75 cases, presenting with chronic tics, seen consecutively in the outpatient clinic of the departments of neurology of the Hospital de Clínicas, Juan P. Garrahan National Pediatrics Hospital and Hospital Frances of Buenos Aires, from 1988 to 1991 . Most patients were referred to us from other clinical departments within our hospitals. The remainder were referrals from 
TABLE I. Motor tics in 75 patients with GTS

\begin{tabular}{|c|c|}
\hline Simple & Complex \\
\hline $\begin{array}{l}\text { Increased blinking rate } \\
\text { Nose wrinkling } \\
\text { Eye winking } \\
\text { Teeth sucking } \\
\text { Eyebrow raising } \\
\text { Gaze raising } \\
\text { Tongue protrusion } \\
\text { Lip biting } \\
\text { Lateral head jerking } \\
\text { Shoulder shrugging } \\
\text { Violent nodding } \\
\text { Random head jerking } \\
\text { Arm indrawing } \\
\text { Hand wringing } \\
\text { Finger drumming } \\
\text { Belly, pelvic and trunkal } \\
\text { jerking } \\
\text { Buttock jerking while } \\
\text { seated } \\
\text { Thoracic jerking } \\
\text { Kicking } \\
\text { Foot flexing } \\
\text { Eye twitching } \\
\text { Forward head jerking } \\
\text { Oromandibular twitching } \\
\text { Other facial twitching } \\
\text { Pouting } \\
\text { Tongue twitching } \\
\text { Limb jerking } \\
\text { Finger crossing } \\
\text { Teeth grinding } \\
\text { Sideway gazing } \\
\text { Arm raising } \\
\text { Mouth angle deviation } \\
\text { Nose twitching } \\
\text { Hand waving } \\
\text { Facial grimacing }\end{array}$ & $\begin{array}{l}\text { Nose touching } \\
\text { Shirt adjusting } \\
\text { Hands and arms sniffing } \\
\text { Object throwing } \\
\text { Face and thigh self-slapping } \\
\text { Hair preening } \\
\text { Leg crossing } \\
\text { Hopping } \\
\text { Trouser adjusting } \\
\text { Strap lifting } \\
\text { Nose blowing }\end{array}$ \\
\hline
\end{tabular}

other hospitals both in Buenos Aires and elsewhere in Argentina.

A comprehensive clinical history was recorded, including age at onset of motor and phonic tics as well as their distribution, clinical phenomenology and progression. Simple motor tics were taken as fast, darting, meaningless jerks; dystonic motor tics comprised abnormal involuntary sustained movements or postures (Jankovic and Stone, 1991); while complex motor tics included more elaborated but purposeless movements. Simple phonic tics were defined as meaningless sounds and noises while complex phonic tics referred to linguistically meaningful words and phrases out of social context. Sensory tics were recorded as such when patients reported a peculiar sensory feeling prior to the appearance of the movement disorder or when a movement could be interpreted as cathartic voluntary action intended to relieve the subjective feeling, though on occasion the motor correlate was lacking. Since tics are often inhibited at examination and even during video recording, not only the examiners' description but also the patients' and their parents' reports were taken into account to determine the tic pattern.

Data were requested on initial diagnosis as well as family history for tics, coprolalia, palilalia (involuntary repetition of the last sound, word, phrase or sentence uttered by the patient), echolalia (as above but regarding the interlocutor's speech), and somniloquias (words or sentences uttered by the patient while asleep). GTS, obsessive-compulsive disorder (OCD) and attention deficit disorder (ADD) were diagnosed according to DSM-III-R (American Psychiatric Association, 1987), while self-injurious behaviour, schooling performance, ethnic origin and perinatal background were also recorded.

\section{RESULTS}

Sixty patients were males, with ages ranging from 6 to 53 years (mean 19.7 years), and 15 were females, with ages ranging from 12 to 55 (mean 22.13 years); overall mean age was 20.02 years.

Mean age at onset of GTS was 7.51 years for males and 8.20 for females, with a mean of 12.58 years of tic duration. While phonic tics were the presenting symptom in $2.7 \%$, the remainder exhibited motor tics. Degree of severity was mild in $6.7 \%$, moderate in $49 \%$ and severe in $44.3 \%$.

According to body segment, 237 motor tics were discerned; 135 involved the face and neck, 55 the upper limbs, 25 the lower limbs and 22 the trunk. Table I lists simple and complex motor tics which were presented in $74 \%$ and $26 \%$ of cases respectively. Presenting motor tics, globally listed in Table II, were overwhelmingly simple in nature $(95 \%)$. Dystonic tics were present in 29 patients and involved the cervical area in 18, orbicular oculi in three, hands in five and masticatory muscles in three, while sensory tics were reported in nine cases.

Phonic tics were detected in all patients, and included mouth rinsing with a swishing noise, hiccoughs, tongue clicking, yelling, screaming, sniffing, ughing, shhing, mumbling, popping, snorting, throat clearing, whistling, clucking, coughing, stuttering, guttural sounds, non-specific utterances, sobbing, isolated words out of context, grunting, teeth chattering, clicking, sighing, giggling, vowel utterances, buzzing, cooing and meaningless cliches.

Out of the 75 GTS cases, $28 \%$ developed coprolalia, $10.7 \%$ copropraxia, $17.5 \%$ echolalia, $4 \%$ echopraxia, $10.8 \%$ palilalia and $12 \%$ somniloquia. 
TABLE II. Presenting motor tic

\begin{tabular}{lr}
\hline Excessive blinking & 41 \\
Lateral head jerking & 10 \\
Forward head jerking & 6 \\
Eye winking & 6 \\
Oromandibular twitching & 5 \\
Shoulder shrugging & 3 \\
Arm raising & 3 \\
Facial grimacing & 3 \\
Tongue twitching & 2 \\
Lip biting & 1 \\
Limb jerking & 1 \\
Teeth grinding & 1 \\
Strap lifting & 1 \\
Thoracic jerking & 1 \\
Finger crossing & 1 \\
Trouser adjusting & 1 \\
Gaze raising & 1 \\
Sideway gazing & 1 \\
Mouth angle deviation & 1 \\
Arm lifting & 1 \\
Nose twitching & 1 \\
Nose blowing & 1 \\
Hand waving & 1 \\
Multifocal jerks & 1 \\
\hline
\end{tabular}

Tics were often precipitated by anxiety in 50.6\% of the cases and by watching TV in $6.6 \%$, while in one there was a clear-cut positive correlation between tic severity and hyperthermia. Tic inhibition was reported to occur during sexual intercourse and while playing games in two each. On occasion, phonic tic suppression was marked enough to exhibit a dramatic rebound phenomenon, as illustrated by a patient who was able to work for hours as a professional fashion model without involuntary utterances.

Despite the handicap caused by tics, schooling was rated as good in $46.7 \%$ of the cases, fair in $4 \%$, bad in $16 \%$ and non-existent in $33.3 \%$.

Positive family history for tics was recorded in $26.6 \%$ of the patients with more than one relative affected in a few cases, while abnormal perinatal events were reported in $32 \%$, including hypoxia in seven, preterm birth in five, umbilical cord round the neck in three, fetal distress in three, forceps delivery in three, and other dystocic deliveries in three each.

OCD was evident in $66 \%$ of cases, ADD in $16 \%$, migraine in $8 \%$, enuresis in $8 \%$, psychiatric illness in $4 \%$ and substance abuse in $8 \%$. OCD included taking objects to pieces in three, and other OCD in eight, including arithmomania, scratching, tidying folders, excessive personal hygiene, switching lights on and off, opening and closing doors and dancing steps in one each.

Twenty-three cases (30.6\%) experienced social embarrassment inducing self-isolation, while in others tics led to job difficulties, divorce, increasing shyness and/or anxiety and even forcible rejection by peers.

Almost half of the cases ( $48 \%$ ) were initially diagnosed as psychogenic. GTS or tics was the initial diagnosis in only $25.4 \%$, epilepsy in three, hyperkinesia in one, behavioural disorders in two and sleep disturbances in one, while it was not available in 13.

Self-injurious behaviour included onychophagia in $62 \%$ of patients, one of whom developed nail removal, lip biting in $9.3 \%$, self-slapping in $10 \%$, one of whom inflicted severe bruises, and hair pulling in one.

Ethnic background comprised $34.6 \%$ Latins, 4\%, Jews, $1.3 \%$ Germans and $1.3 \%$ Arabs, and was mixed or could not be determined in the remainder.

Thirty-four patients were treated with flunarizine $10 \mathrm{mg} /$ day for 3 months and evaluated fortnightly by means of the Goetz rating scale (Goetz et al., 1987b) as part of a separate protocol, while haloperidol was given to 29 , clonazepam to four, tiapride to nine, clonidine to five, pimozide to seven, and tetrabenazine to one. Table III summarizes drugs administered and results achieved.

\section{DISCUSSION}

Although diverse series of GTS patients have been reported from different countries world-wide, very few publications from Latin America are available, probably due to the fact that many if not most of such cases are misdiagnosed and hence improperly treated.

Our series from Argentina demonstrated that GTS in Latin America shares striking similarities with cases reported elsewhere, thus confirming the universal cross-cultural uniformity previously described (Shapiro et al., 1978; Nomura and Segawa, 1982; Asam, 1982; Lieh Mak et al., 1982; Lees et al., 1984; Min and Lee, 1986; Robertson and Trimble, 1991). Inhabitants of Argentina and particularly its capital city Buenos Aires are mostly of European descent, as shown by the ethnic background of our patients who included $34.6 \%$ Latins, $4 \%$ Jews, $1.3 \%$ Germans and $1.3 \%$ Arabs, while for the remainder no single ethnos could be pinpointed. This pattern roughly parallels the prevailing general population profile in Buenos Aires with no ethnic group being overrepresented.

Age at onset, tic features, male predominance and cephalocaudal progression disclosed no differences with previous studies on European, American and Asian patients (Lieh Mak et al., 1982; Shapiro and Shapiro, 1982; Shapiro et al., 1983; Lees et al., 1984; Min and Lee, 1986; Robertson and Trimble, 1991). 
TABLE III. Drugs used and benefit achieved in 75 cases of GTS

\begin{tabular}{lcccc}
\hline Drug & Evident benefit & Slight benefit & No benefit & Undetermined \\
\hline Flunarizine & 18 & 5 & 8 & 3 \\
Biperiden & & 3 & & 2 \\
Diazepam & 10 & 3 & 14 & \\
Haloperidol & 3 & 1 & 5 & 1 \\
Tiapride & 5 & 2 & & \\
Tetrabenazine & 1 & 1 & 2 & \\
Pimozide & 1 & & \\
Clonazepam & & & & \\
\hline
\end{tabular}

Incidence of familial cases in our population was low $(26.6 \%)$ compared to other series in the literature. However our study was not designed to explore the familial nature of this disorder and the incidence of a positive family history was only obtained through questioning of the patient and parents. We are fully aware of the shortcomings of the family history method of ascertainment (Pauls et al., 1984) as compared with direct interview methods used in genetic studies (Eapen et al., 1993).

Argentine cases are frequently misdiagnosed even by a specialist, for whom a correct diagnosis seems to be a major accomplishment. Admittedly, referral bias may well be present in our series, though its influence should not be exaggerated as degree of severity was not an issue but rather initial misdiagnosis followed by improper treatment. A total of $48 \%$ of our cases were interpreted as purely psychogenic and treated as such, while epilepsy was incorrectly diagnosed in three. Interestingly, even after a firm diagnosis of GTS was reached, psychiatrists and/or psychologists previously treating such cases were reluctant to disregard the putative psychogenic nature of the disorder. In all likelihood this was due on one hand to the fact that anxiety often affected tic severity either for better or worse and, on the other hand, to the strong psychoanalytic background of local psychiatrists. In support of this contention, on reviewing most Latin American papers published in regional journals, a psychological interpretation of several aspects of the disease is commonly advanced.

Nearly $62 \%$ of our patients had varying degrees of onychophagia, so severe in one as to remove nails forcibly, and a further one had trichotillomania. Both onychophagia and trichotillomania are interpreted as a self-injurious behaviour indicative of OCD, which is frequently associated with GTS (Robertson et al., 1988; George, 1991). Onychophagia is responsive to clomipramine, a drug reported to be effective for OCD and trichotillomania (Leonard et al., 1991). Recent studies suggest that GTS and OCD may be aetiologically and even genetically related. It has been proposed that OCD could be a behavioural phenotype of the putative GTS gene(s) (Pauls et al., 1986a,b; Eapen et al., 1993).

Although self-injurious behaviour in GTS has been reported in the literature (Robertson et al., 1989) the occurrence of onychophagia has hardly ever been described, despite being a common association in our patients, perhaps due to its $50 \%$ plus prevalence in normal adolescents, which drops to $23 \%$ in later life (Leonard et al., 1991). Lip biting and self-slapping were also frequent in our series. In spite of being poorly detected, self-injurious behaviour is probably common in even mild GTS cases.

Another remarkable finding in our patients was the high incidence of birth trauma and other pathologic perinatal events, which were present in $26.6 \%$ of cases. Similar findings have been reported by Lees $e t$ al. (1984) in $25 \%$ and Lucas et al. (1982) in $40 \%$ of their series.

Coprolalia was observed in 21 patients, four of whom had only mental coprolalia. The prevalence in our series $(28 \%)$ is almost identical to the figure reported from Denmark (Regeur et al., 1986). The prevalence of this disorder in GTS patients worldwide is outlined in Table IV.

The most common foul words were "dick" and "cunt" which were sometimes expressed only partially. However, the River Plate Spanish "puta", "pija" and "concha" have two syllables and finish in a vowel, thus sounding more pungent than their English equivalents. Conversely, the most frequently pronounced foul words in English are "fuck" and "shit", perhaps not because of their connotations but rather because they are composed of high-probability sequences of letters or phonemes as proposed by Nuwer (1982). Curiously enough, the local term for "fuck", "coger" is seldom used perhaps because it ends in a consonant and therefore sounds weak.

So far it cannot be ascertained whether the unexpected occurrence of offensive language attributed by

78 Behavioural Neurology . Vol 8 . 1995 
GILLES DE LA TOURETTE SYNDROME IN ARGENTINA

TABLE IV. Coprolalia: comparison between different GTS populations

\begin{tabular}{lcl}
\hline Country & Coprolalia prevalence & \multicolumn{1}{c}{ Reference } \\
\hline USA & $22-32 \%$ & Shapiro et al. (1978) \\
UK & $37 \%$ & Goetz et al. (1992) \\
The Netherlands & $36 \%$ & Lees et al. (1984) \\
Korea & $33 \%$ & Van de Wetering et al. (1988) \\
Argentina & $28 \%$ & Min and Lee (1986) \\
Denmark & $26 \%$ & Present series \\
Japan & $4 \%$ & Regeur et al. (1986) \\
Brazil & $0 \%$ & Nomura and Segawa (1982) \\
\hline
\end{tabular}

Bennet $(1976,1977)$ and Nuwer (1982) to random generation of high-probability phonemes may be extrapolated to our Spanish-speaking population. Here such a contention should be weighed against the finding by Lang et al. (1993) of a patient who developed coprolaliopraxia at times without concurrent vocalizations or the associated word coming to mind, while training in sign language as part of a rehabilitation worker programme.

Neuroleptics including haloperidol have provided clear-cut benefits for tic control. However, due to their side effects only one-third of patients improving on treatment choose to continue therapy on a longterm basis (Shapiro et al., 1983). Curiously enough only half of our patients receiving haloperidol showed any improvement, in disagreement with most reports (Shapiro et al., 1989). The usefulness of clonidine, a drug widely employed in GTS, is also a matter of controversy (Goetz et al., 1987a). Given the initial good results achieved in GTS with flunarizine (Micheli et al., 1990), a calcium entry blocker with mild D2 blocking activity, we have so far treated 34 patients with $53 \%$ overall improvement and good compliance. Doses ranged from 10 to $30 \mathrm{mg} /$ day with a mean of $15 \mathrm{mg} /$ day. Out of $53 \%$ of patients benefiting from treatment, all decided to continue on a long-term basis, $23.5 \%$ of whom developed side effects including mild parkinsonian signs and depression which promptly improved on dose reduction.

Our present findings from the first large Argentinian series show that GTS in Latin America exhibits a pattern of tic expression not dissimilar to that described elsewhere.

\section{REFERENCES}

American Psychiatric Association (1987) Diagnostic and Statistical Manual of Mental Disorders, 3rd edn, revised. APA, Washington, DC.

Asam V (1982) A follow-up study of Tourette syndrome. In: Gilles de la Tourette Syndrome (Eds TN Chase and AJ Friedhoff), pp. 285-286. Raven Press, New York.
Bennett WR (1976) Scientific and Engineering Problem Solving with the Computer. Prentice-Hall, Englewood Cliff, NJ.

Bennett WR (1977) How artificial is intelligence? American Scientist, 65, 694-702.

Chouza C (1986) Aspectos diagnósticos y terapéuticos de los tics. Revista Neurologica de Argentina, 12, 265-273.

Eapen V and Robertson MM (1992) Gilles de la Tourette syndrome. A case report from Guyana in South America. Behavioural Neurology, 5, 39-41.

Eapen V, Pauls DL and Robertson MM (1993) Evidence for autosomal dominant transmission in Tourette's syndrome. United Kingdom cohort study. British Journal of Psychiatry, 162, 593-596.

Fontanari JL and Vaitses VDC (1985) Tiques, multiplos tiques e syndrome de Gilles de la Tourette: estudo de 11 casos e revisao de la literatura. Revista Psiquiatrica Rio Gd do Sul, 7, 11-22.

Fontanari JL and Vaitses VDC (1986) Sindrome de Gilles de la Tourette em multiplos tiques: estudo clinico de 15 casos e revisao de la literatura. Neurobiologia, 49, 109128.

George MS (1991) Obsessive-compulsive disorder. International Clinical Psychopharmacology, Suppl 3, 57-63.

Gilles de la Tourette G (1885) Etude sur une affection nerveuse caracterisee par de l'incordination motrice, accompgnee de echolalie et de coprolalie. Archives Neurologique (Paris), 9, 1942, 158-200.

Goetz CG, Tanner CM, Wilson RS et al. (1987a) Clonidine and Gilles de la Tourette's syndrome: a double-blind study using objective rating methods. Annals of Neurology, 21, 307-310.

Goetz CG, Tanner CM, Wilson RS and Shannon KM (1987b) A rating scale for Gilles de la Tourette syndrome. Description reliability and validity data. Neurology, 37, 1542-1544.

Goetz CG, Tanner CM, Stebbins GT, Leipzig G and Cavi WC (1992) Adult tics in Gilles de la Tourette's syndrome. Description and risk factors. Neurology, 42, 784-788.

Golfeto JH, Loureiro SR and Ribeiro MUM (1988) O sindrome de Gilles de la Tourette: estudo de um caso. Neurobiologia, 51, 189-202.

Guajardo V (1986) Sindrome de Gilles de la Tourette: revisión de aspectos clínicos y neuroquímicos. A propósito de un caso clínico. Revista Chilena de Neuro-psiquiatria, 24(2), 108-111.

Itard JMG (1825) Memoire sur quelques fonctions involuntaires des appareils de la locomotion de la prehension et de la voix. Archives of General Medicine, 8, 385-407. 
Jankovic J and Stone L (1991) Dystonic tics in patients with Tourette's syndrome. Movement Disorders, 6, 248252.

Joy Sobrino JL, Rivera Reyes L and Aviles Michel R (1985) Gilles de la Tourette: an underdiagnosed disorder. Boletin de la Asociacion Medica de Puerto Rico, 77, 202206.

Lang AE, Consky E and Sandor P (1993) "Singing tics" insights into the pathophysiology of symptoms in Tourette's syndrome. Annals of Neurology, 33, 212-215.

Lees AJ, Robertson M, Trimble MR and Murray NMF (1984) A clinical study of Gilles de la Tourette syndrome in the United Kingdom. Journal of Neurology, Neurosurgery and Psychiatry, 47, 1-8.

Leonard HL, Lenang MC, Swedo SE, Retten DC and Rapoport JL (1991) A double-blind comparison of clomipramine and desipramine treatment of severe onychophagia (nail biting). Archives of General Psychiatry, 48, 821-827.

Lieh Mak F, Chung SY and Lee P (1982) Tourette syndrome in the Chinese: a follow-up of 15 cases. In: Gilles de la Tourette Syndrome (Eds AJ Friedhoff and TN Chase), pp. 277-283. Raven Press, New York.

Lucas AR, Beard CM, Rajput AH et al. (1982) Tourette syndrome in Rochester, Minessota. In: Gilles de la Tourette Syndrome (Eds AJ Friedhoff and TN Chase), Adv Neurol 1982; Vol 35. Raven Press, New York.

Matarazzo EB (1985) Etiologia encefalitica na sindrome de Gilles de la Tourette. Revista Psiquiatria Clin (Sao Paulo), 12, 81-92.

Micheli F, Gatto M, Lekhuniec E, Mangone C, Fernandez Pardal M, Pikielny R and Casas Parera I (1990) Treatment of Tourette's syndrome with calcium antagonists. Clinical Neuropharmacology, 13, 77-83.

Min SK and Lee H (1986) A clinical study of Gilles de la Tourette's syndrome in Korea. British Journal of Psychiatry, 149, 644-647.

Nardy AE and Tosted LRM (1987a) Sindrome de Gilles de la Tourette. Paradigma Neuropsiquiatrico (1 ra. parte). Journal Brasileiro de Psiquiatria, 36, 145-150.

Nardy AE and Tosted LRM (1987b) Gilles de la Tourette: etiologia e tratamento (2da. parte). Journal Brasileiro de Psiquiatria, 36, 217-222.

Nomura $Y$ and Segawa M (1982) Tourette in oriental children: clinical and pathophysiological considerations. In: Gilles de la Tourette Syndrome (Eds AJ Friedhoff and and TN Chase), pp. 277-280. Raven Press, New York.

Nuwer MR (1982) Coprolalia as an organic symptom. In: Gilles de la Tourette Syndrome (Eds AJ Friedhoff and TN Chase, pp. 363-368. Raven Press, New York.

Obeso JA, Rothwell JC and Marsden CD (1981) Simple tics in Gilles de la Tourette's syndrome are not prefaced by a normal premovement EEG potential. Journal of Neurology, Neurosurgery and Psychiatry, 44, 735-738.
Pauls DL, Kruger SD, Leckman JF et al. (1984) The risk of Tourette's syndrome and chronic multiple tics among relatives of Tourette's syndrome patients obtained by direct interview. Journal of the American Academy of Child and Adolescent Psychiatry, 23, 134-137.

Pauls DL, Leckman JF, Towbin KE et al. (1986a) A possible genetic relationship exists between Tourette's syndrome and obsessive-compulsive disorder. Psychopharmacology Bulletin, 22, 730-733.

Pauls DL, Towbin KE, Zahwer GEP et al. (1986b) Gilles de la Tourette syndrome and obsessive-compulsive disorder. Archives of General Psychiatry, 43, 1180-1182.

Regeur L, Pakkenberg B, Fog R et al. (1986) Clinical features and long term treatment with pimozide in 65 patients with Gilles de la Tourette's syndrome. Journal of Neurology, Neurosurgery and Psychiatry, 49, 795-796.

Robertson MM, Trimble MR and Lees J (1988) The psychopathology of Gilles de la Tourette syndrome: a phenomenological analysis. British Journal of Psychiatry, 152 283-290.

Robertson MM and Trimble MR (1991) Gilles de la Tourette syndrome in the Middle East. Report of a cohort and a multiply affected large pedigree. British Journal of Psychiatry, 158, 416-419.

Rolemberg JC, Andrade Filho AS, Ribeiro BS, Lima JMPF and Sena PG (1985) Doenca de Gilles de la Tourette: registro de um caso. An Acad Med Bahia, 6107-6114.

Shapiro AK and Shapiro E (1982) Tourette syndrome: history and present status. In: Gilles de la Tourette Syndrome (Eds AJ Friedhoff and TN Chase). Raven Press, New York.

Shapiro AK, Shapiro ES, Bruun RD and Sweet RD (1978) Gilles de la Tourette Syndrome. Raven Press, New York.

Shapiro AK, Shapiro E and Eisenkraft GY (1983) Treatment of Gilles de la Tourette's syndrome with clonidine and neuroleptics. Archives of General Psychiatry, 40, $1235-1240$.

Shapiro E, Shapiro AK, Fulop G et al. (1989) Controlled study of haloperidol, pimozide and placebo for the treatment of Gilles de la Tourette's Syndrome. Archives of General Psychiatry, 46, 722-730.

Sougey EB and Vilaca MR (1981) Sindrome de Gilles de la Tourette. Estudo de um caso. Neurobiologia, 44, 39-52.

Van de Wettering BJM, Cohen AP, Minderaa RB et al. (1988) Het Syndroom van Gilles de la Tourette: klinische bevindingen. Nederland Tijdschrift voor Genneskunde, 87, 181-186.

Warton D (1987) La enfermedad de Gilles de la Tourette: revisión a propósito de un caso. Rev Neuro-Psiquiatria, 50, 36-46.

(Received 20 September 1994; accepted as revised 19 June 1995) 


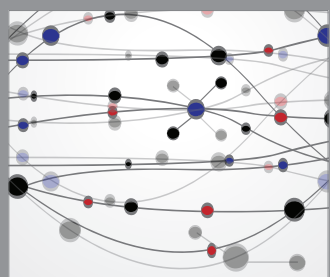

The Scientific World Journal
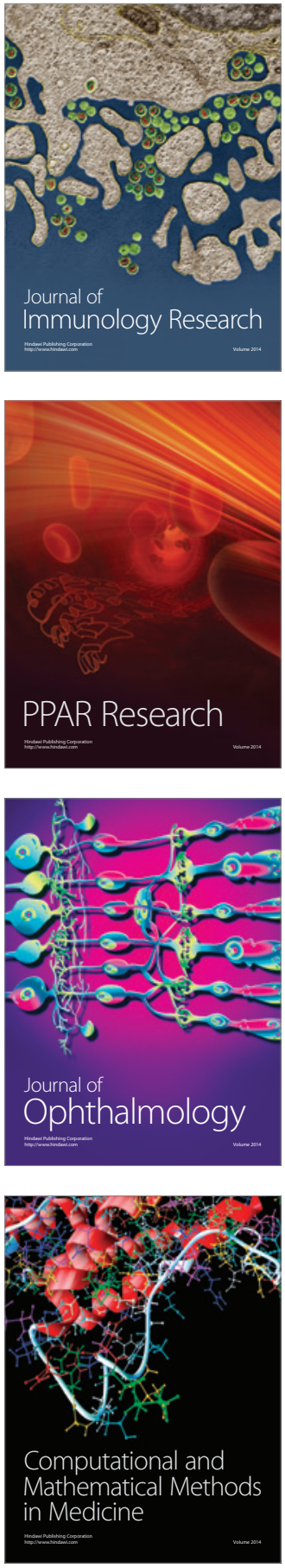

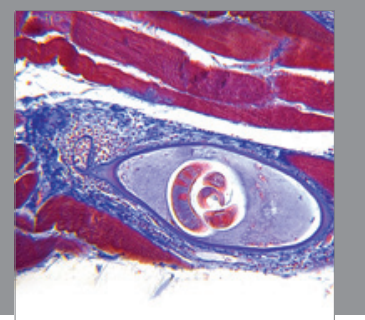

Gastroenterology

Research and Practice
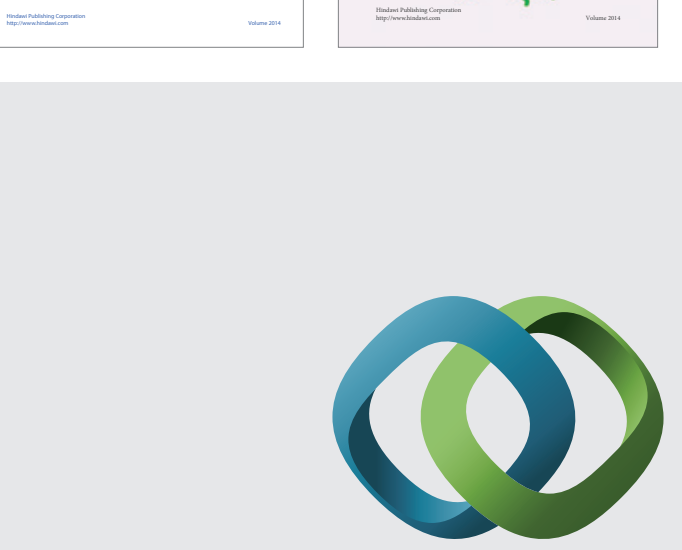

\section{Hindawi}

Submit your manuscripts at

http://www.hindawi.com
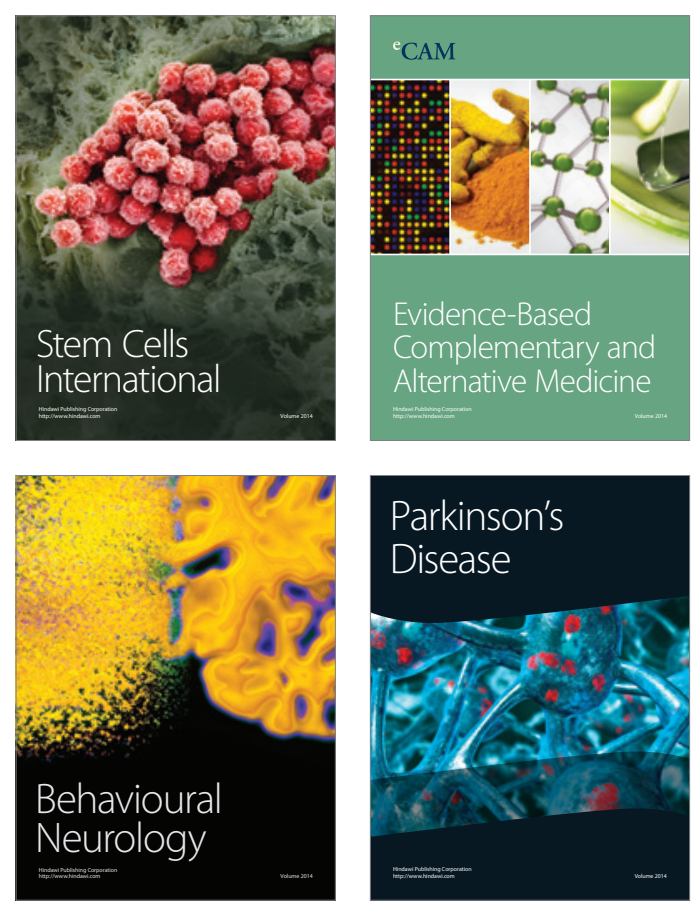

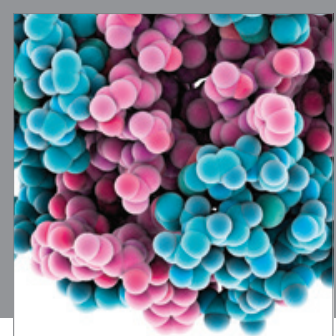

Journal of
Diabetes Research

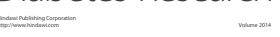

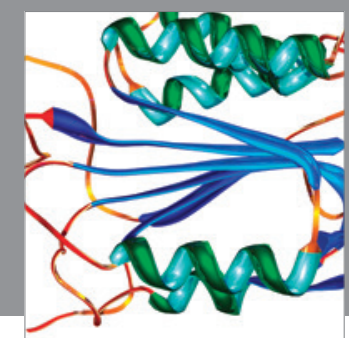

Disease Markers
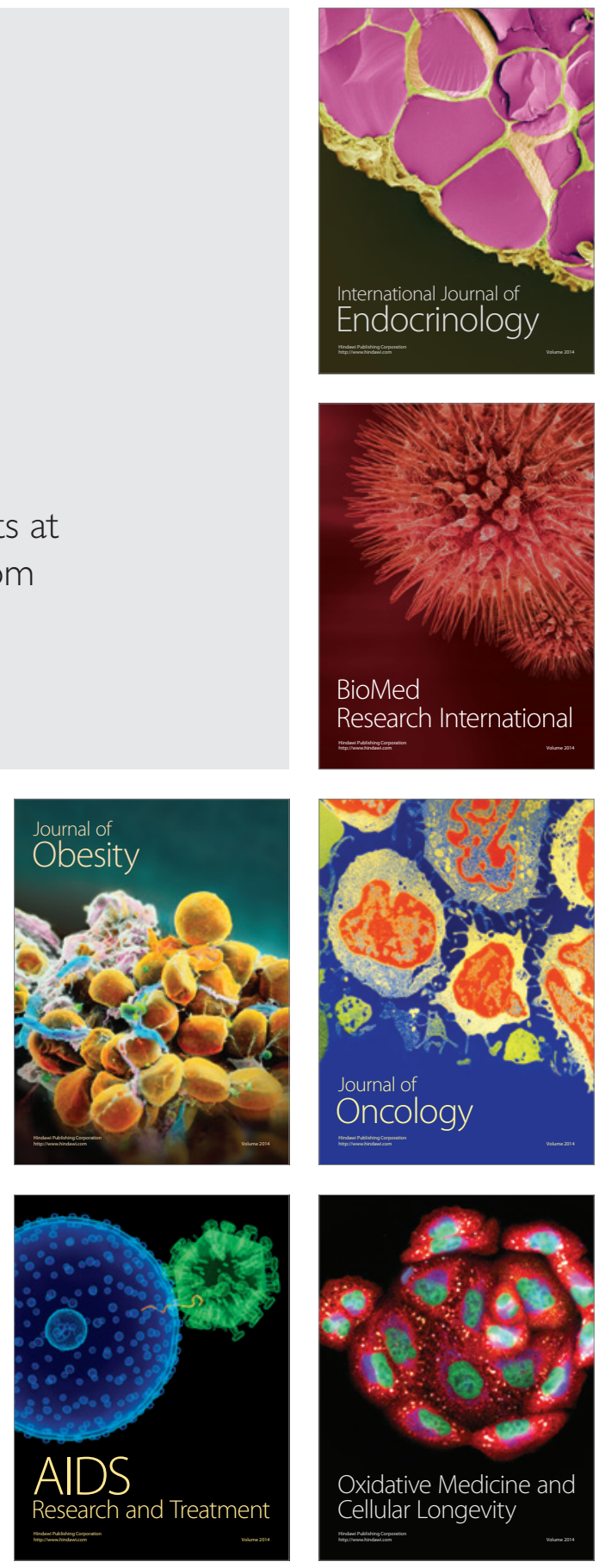